Marketing in Asia Group

Asian Journal of Business Research

Volume 9 Issue 2, 2019

ISSN 2463-4522 e-ISSN 1778-8933

DOI: $10.14707 / a j b r .190063$

\title{
Forecasting Financial Vulnerability in Malaysia: A Non- parametric Indicator Approach
}

\author{
Mohammad Affendy Arip \\ Faculty of Economics and Business, Universiti Malaysia Sarawak, Malaysia \\ Tai Hock Kuek \\ Faculty of Economics and Business, Universiti Malaysia Sarawak, Malaysia \\ Chin Hong Puah \\ Faculty of Economics and Business, Universiti Malaysia Sarawak, Malaysia
}

\begin{abstract}
The present study attempts to examine episodes of financial vulnerability and develop a financial vulnerability indicator for the Malaysian financial market. Spanning the period of 1997 to 2017, a total of 11 variables of monthly frequency from different aspects of the financial market and economy as a whole are aggregated into an indicator in order to gauge financial vulnerability. Empirical findings indicate that the constructed financial vulnerability indicator has successfully traced episodes of financial vulnerabilities in Malaysia. Specifically, the indicator that contains forecasting ability could act as a leading indicator in forecasting financial vulnerabilities in Malaysia. Moreover, the insights provided by the indicator would be useful in policy response formulation.
\end{abstract}

Keywords: Financial Crises, Financial Vulnerability Indicator, Principal Component Analysis, Malaysia

Publication Details: Received 25 Jan 2019; Revised 14 Feb 2019; Accepted 4 July 2019 


\section{Introduction}

In mid-2007, the deteriorating quality of sub-prime assets in the US became an outbreak of the global financial crisis in 2008. The failure in the US and global financial institutions have led to a shutdown of the interbank and credit markets in which the spillover effect was greatly impacted Asian economies, including Malaysia, through the financial and trade interlinkages (Bank Negara Malaysia, 2009). To boost the domestic economy, the Malaysian government has implemented various stimulus packages and policies to encourage investment in the property market through the exemption of a real property gains tax.

In turn, the property sector became an attractive form of investment for domestic and foreign investors. After 2009, demand for and investment in the Malaysian property market surged, especially for residential properties. The escalation in property demand, in which the total value of property sales in the country was recorded at an average increasing rate of 30 percent from 2009 to 2011, has driven the upsurge in property prices. In 2012, the Malaysian House Price Index (MHPI) has registered a strong rise from an annual growth rate of 3.2 percent in the preceding 10-year period to a rate exceeding 10 percent. These sharp rises in property values induced massive concerns regarding the sustainability of such price hikes.

Highly open and diversified economy of Malaysia was hit by a number of external and domestic shocks towards 2015. The oversupply of crude oil, coupled with declining demand, smashed the global market at a time where the economies of Europe and a number of developing countries were weakening towards October 2015. This impacted Malaysia's crude oil export as a net oil-exporting country due to plunging crude oil prices. Moreover, the spill-overs from China, with its sluggish growth, impacted negatively on emerging market economies. Emerging market economies with a declining currency value, including Malaysia, became less attractive for investment and thus suffered capital outflows.

Though private consumption has boosted the economy since the global financial crisis, the attractiveness of the property market has incited concern regarding the level of household indebtedness. Since 2008, the household debt to gross domestic product (GDP) ratio has posted an upsurge of 25.1 percent to hit the highest ratio of 89.1 percent in 2015. Although cooling measures have been implemented, the ratio has still hovered around this worrying level, recorded at 84.3 percent in 2017 . With the limiting policy space reacting to shocks due to high federal debt and contingent liabilities, the relatively high household debt remained a key vulnerability (International Monetary Fund, 2017). Though credit expansion plays a part in economic development, unsustainable credit growth would lead to severe consequences for the financial market and economy. Typically, asset price busts and credit crunches bring about more severe downturns as compared to other slumps (Claessens \& Kose, 2013).

To decrease the impact of financial vulnerabilities, the construction of leading indicators is crucial to provide early warning of macroeconomic and financial vulnerabilities for the financial system and economy as a whole. Such financial vulnerability indicators could serve as a forecasting tool in predicting the financial development in Malaysia as well as monitor the impending sources of financial 
vulnerabilities to the system. Therefore, the present study attempts to examine episodes of financial vulnerability and develop a financial vulnerability indicator for the Malaysian financial market.

\section{Literature Review}

In general terms, financial vulnerability can be thought of as vulnerabilities of the financial system to shock or disturbances. Financial vulnerability, due to imbalances in the financial system, could cause the risk of unexpected corrections to the system and even reduce its ability to endure other shocks. As financial liberalization takes place, financial vulnerability tends to pick up more than one aspect through which it becomes multidimensional. Thus, monitoring a single indicator on financial vulnerabilities can hardly be an effective measurement. As such, blending a series of indicators into a composite leading indicator would serve as a warning system in gauging the vulnerabilities in the financial market. The construction of early warning system to financial vulnerabilities could serve as a forecasting tool in predicting the financial development and monitoring the impending sources of financial vulnerabilities.

Though interest in early warning system development has been renewed after the global financial crisis in 2008, the research on early warning of financial vulnerabilities dates back to 1996. Prior to the Asian financial crisis, Kaminsky and Reinhart (1996, 1999) proposed a non-parametric signals approach in assessing a country's vulnerability to crises. The signals approach was later extended into indicator construction by Bruggemann and Linne (2002) and Edison (2003) for financial crisis detection. Bruggemann and Linne (2002) discovered the predictive ability of exchange rate, exports and currency reserves in crisis vulnerabilities assessment. Prior to the outbreak of the global financial crisis, Illing and Liu (2006) carried out research to construct the Canadian Financial Stress Index (FSI) using factor analysis, credit aggregate-based weights, variance-equal weights, and the sample cumulative distribution functions transformation approach. They noted that accuracy in stress characterization was important in financial crisis forecasting.

With the renewed interest in an early warning mechanism, Cardarelli et al. (2011) and Balakrishnan et al. (2011) examined the relationship between financial stress and economic contractions in advanced economies and the emerging market, respectively, using a variance equal weighting procedure. Cardarelli et al. (2011) added that banking distress had a higher tendency to result in longer economic downturns. Hakkio and Keeton (2009) and Cevik et al. (2013) considered principal component analysis in constructing a financial stress index. Cevik et al. (2013) developed an FSI for Turkey regarding a financial stress assessment through which they discovered the usefulness of the constructed index with its leading attribute for the Turkish economy in addition to a linkage between the FSI and the real economy. Early warning system has also been applied in other fields, such as property and business cycle, as conducted by Puah et al. (2016) and Abu Mansor et al. (2015). Additionally, Megersa and Cassimon (2015), Nguyen and Duy (2017), and Puah et al. (2017) assessed the vulnerabilities in Ethiopia, Vietnam and Thailand, respectively, based on the signals approach. Megersa and Cassimon (2015) highlighted the prominence of local and international dynamics in vulnerabilities toward financial crises while Puah et al. 
(2017) noted that financial crises are typically led by weak exports, economic slowdown and house price decline.

\section{Data and Methodology}

In this paper, an indicator construction approach is implemented to construct a financial vulnerability indicator for the Malaysian financial market. Accordingly, a principal component analysis is used to construct the financial vulnerability indicator (FVI) for the case of Malaysia, as in Hakkio and Keeton (2009) and Cevik et al. (2013). Indicators from the financial market, property sector, and macroeconomic sense will be considered for the FVI construct to gauge financial vulnerability. As Drehmann and Juselius (2014) discovered the usefulness of the credit-to-GDP measure in vulnerabilities assessment, the credit-to-GDP ratio is employed as a benchmark to financial vulnerabilities in this study.

The construction of the FVI based on principal component analysis utilizes indicators from the financial market, property market, and macroeconomic variables. From that, all of the indicators can be categorized into four sub-groups, namely the real sector, financial sector, external sector, and capital account. The real sector comprises the consumer price index, industrial production index, housing approvals, and share price, while the financial sector is measured by monetary aggregate M2, loans and advances, and short-term interest rate KLIBOR. The indicators categorized under the external sector include exports, imports, and the real effective exchange rate, while total reserve is the measurement of capital account.

In order to evaluate the forecasting ability of the constructed indicator, the PesaranTimmermann test (PT test) is implemented to achieve this purpose. The PT Test is proposed by Pesaran and Timmermann (1992) as a statistical assessment of directional accuracy in forecasting. It is a measurement of whether the success ratio is significantly different from the value obtained when the realised values $y_{t}$ and the forecasts $\hat{y}_{t}$ are independent. Following the notation, the test statistic is presented by

$$
D A=\frac{\sqrt{T}(H R-F R)}{\left(\frac{\hat{P}_{y}\left(1-\hat{P}_{y}\right)}{\bar{y}(1-\tilde{y})}\right)^{1 / 2}}
$$

where $\bar{y}$ is the $T$-month sample average of the binary variable $y_{t}$, the hit rate $H R=$ $\frac{\hat{y}^{u u}}{\hat{y}^{u u}+\hat{y}^{d u}}$, and false rate $F R=\frac{\hat{y}^{u d}}{\hat{y}^{u d}+\hat{y}^{d d}}$. Finally, $\hat{P}_{y}=\bar{z} H R+(1-\bar{z}) F R$. The test statistic above has an asymptotic standard normal distribution under the null hypothesis that $y_{t}$ and $\hat{y}_{t}$ are of independent distribution. Pesaran and Timmermann (2009) provide a suggestion to extend the above test statistic. The extended version is a predictability assessment that is more suitable for market timing when $y_{t}$ and $\hat{y}_{t}$ are serially correlated. The extended test statistic can be denoted as:

$$
P T=(T-1)\left(S_{y y, w}^{-1} S_{y \hat{y}, w} S_{\hat{y} \hat{y}, w}^{-1} S_{\hat{y} y, w}\right) \sim x_{1}^{2},
$$

where 


$$
\begin{gathered}
S_{y y, w}=(T-1)^{-1} Y^{\prime} M_{w} Y, \\
S_{\hat{y} \hat{y}, w}=(T-1)^{-1} \hat{Y}^{\prime} M_{w} \hat{Y}, \\
S_{\hat{y} y, w}=(T-1)^{-1} \hat{Y}^{\prime} M_{w} Y, \\
S_{y \hat{y}, w}=(T-1)^{-1} Y^{\prime} M_{w} \hat{Y}, \\
M_{w}=I_{T-1}-W\left(W^{\prime} W\right)^{-1} W^{\prime}, \\
W=\left(\tau_{T-1}, Y_{-1}, \hat{Y}_{-1}\right),
\end{gathered}
$$

and $Y=\left(y_{2}, \ldots y_{T}\right)^{\prime}, \hat{Y}=\left(\hat{y}_{2}, \ldots \hat{y}_{T}\right)^{\prime}, Y_{-1}=\left(y_{1}, \ldots y_{T-1}\right), \hat{Y}_{-1}=\left(\hat{y}_{1}, \ldots \hat{y}_{T-1}\right)$, and $\tau_{t}$ is a $(T-1) \times 1$ vector of ones. For $Y$ and $\hat{Y}$ notation, $Y$ is the vector of time series while $\hat{Y}$ is a forecast vector of the event. Both the Pesaran and Timmermann (1992, 2009) tests are particularly useful in model assessment of out-of-sample forecasting performance. The forecasting ability of the constructed FVI is assessed against the cyclical component of credit-to-GDP ratio, which is extracted using the Christiano and Fitzgerald (2003) band-pass filter.

The present study employs data from the financial market, property market, and macroeconomic sense in the indicator construction procedures. The period under study spans from January 1997 through December 2017. All of the data are available in monthly frequency, excluding the credit-to-GDP ratio, which is interpolated from quarterly to monthly series using the Chow-Lin (1971) interpolation technique. All of the data and the credit-to-GDP ratio are compiled from CEIC Database and Bank for International Settlements, respectively.

\section{Result and Discussion}

The evolution of FVI is illustrated in Figure 1. Based on the constructed FVI, five vulnerable episodes of the Malaysian financial market have been successfully traced. Chronologically, the economy of Malaysia is adversely impacted by the Asian financial crisis in 1998 and the global financial crisis in 2008. Moreover, the Malaysian economy only experienced slowdown due to vulnerable episodes of the global commodity price hike in 2006 , the property price hike in 2012 , and the global economic meltdown in 2016.

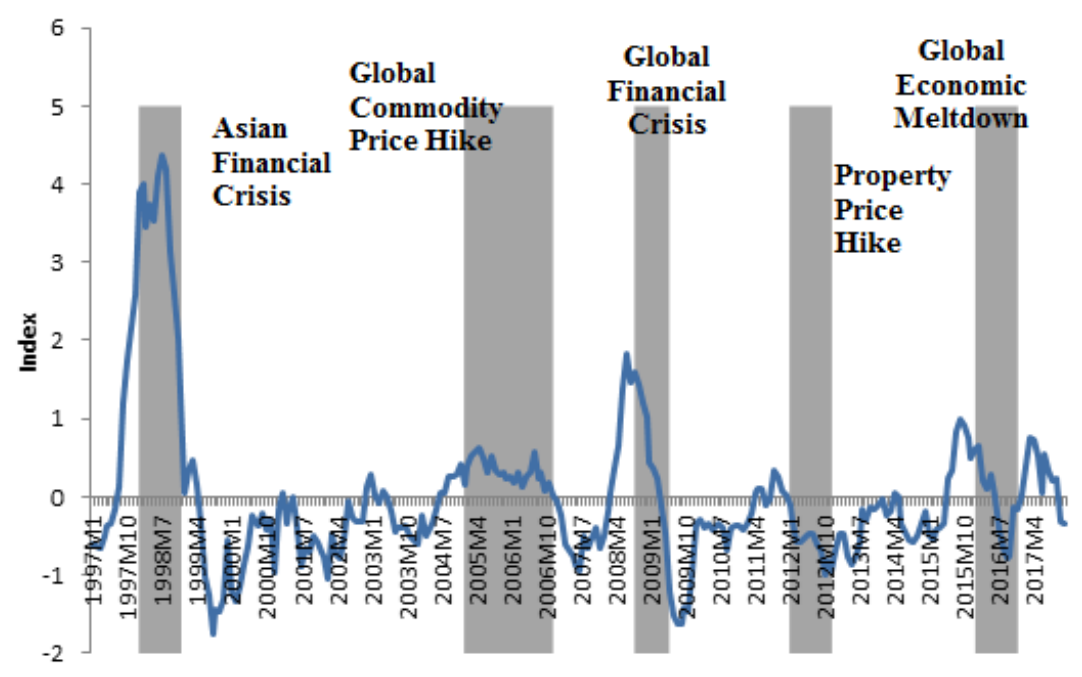

Figure 1: Graph of FVI 
The purpose of sub-group decomposition facilitates tracking the source of financial vulnerabilities in different episodes shown in Figure 2. Primarily, high financial vulnerability is driven by external sector variables leading to a downturn in the real sector during the Asian financial crisis in 1998, the global financial crisis in 2008, and the global economic meltdown in 2016. Contrary to that, improved investment sentiment in the real sector and the financial sector contributed fairly to the low vulnerability environment after the Asian financial crisis in 1998 and before the leadup to the property price hike in 2012 .

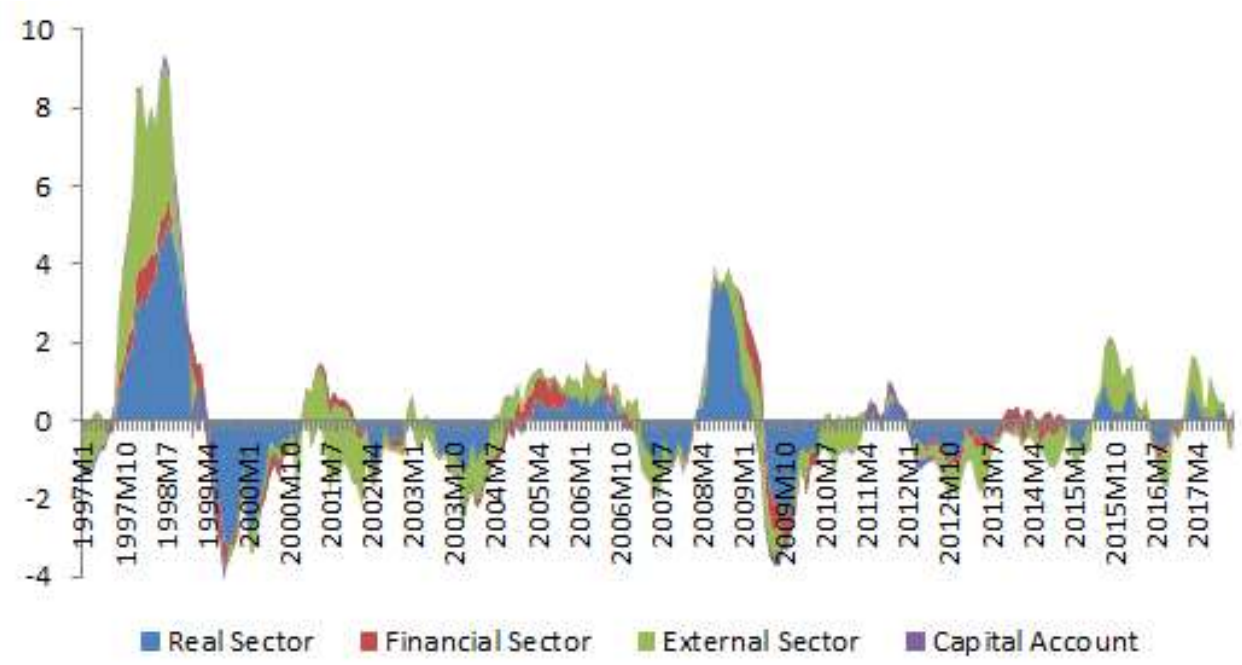

Figure 2: Contribution of Indicators from Sub-Groups

To evaluate the forecasting ability of the constructed indicator, the PT test is implemented to achieve this purpose. The cyclical component of the credit-to-GDP ratio is employed as a benchmark for financial vulnerability in which it is utilized to assess the forecasting ability of the constructed FVI. The summary of PT scores and its p-value are presented in Table 1. From lag 0 to lag 3, the FVI recorded PT scores between 1.284 and 2.237 at the 10 percent significance level. The empirical outcome suggests that the constructed FVI contains the forecasting ability in predicting fluctuations of the financial development in Malaysia.

Table 1: Summary of PT Scores

\begin{tabular}{ccc}
\hline \multirow{2}{*}{ Lag } & \multicolumn{2}{c}{ FVI on Credit-to-GDP } \\
\cline { 2 - 3 } & PT Score & P-Value \\
\hline 0 & 2.237 & $0.013^{*}$ \\
\hline 1 & 1.665 & $0.048^{*}$ \\
\hline 2 & 1.352 & $0.088^{*}$ \\
\hline 3 & 1.284 & $0.100^{*}$ \\
\hline
\end{tabular}

Note: The asterisk $*$ denotes significance level at 10 percent. 


\section{Conclusion}

In the past 21 years, the financial market and economy of Malaysia have experienced several episodes of financial vulnerability. The present study examined episodes of financial vulnerability in Malaysia for the period spanning from 1997 to 2017. Using a principal component analysis, the financial vulnerability indicator is constructed based on variables from different aspects, namely the real sector, financial sector, external sector, and capital account. The variables of consumer price index, industrial production index, housing approvals, share price, monetary aggregate M2, loans and advances, short-term interest rate KLIBOR, exports, imports, real effective exchange rate, and total reserve are aggregated into a financial vulnerability indicator. Acting as a leading indicator, the constructed indicator has successfully captured episodes of financial vulnerability in Malaysia. To assess its forecasting ability, the constructed FVI is assessed against the cyclical component of credit-to-GDP ratio, which indicates that the constructed indicator offers forecasting ability with leading attributes.

As a developing economy, the external sector is particularly important as a source of income from the foreign exchange market. Through the exchange rate policy, monitoring of exchange rate valuations would maintain the competitiveness of domestic products in the international market. Though investment is constructive in boosting the real sector of the economy, particularly foreign investment, tight monitoring and policies on property price and credit expansion are also necessary to prevent impending vulnerabilities towards a more severe downturn, starting with control over speculative activities (Jayaraman et al., 2017). In short, measuring financial vulnerability not only provides a quantitative benchmark to assess the source of vulnerability, but also gives insight into the establishing policy response.

\section{Acknowledgement}

Financial supports from Universiti Malaysia Sarawak (UNIMAS) and Fundamental Research Grant Scheme [F01/FRGS/1493/2016] are gratefully acknowledged.

\section{References}

Abu Mansor, S., Liew, V. K. S., Puah, C. H., \& Wong, S. S. L., (2015), An early warning indicator of economic vulnerability constructing for Malaysian economy, Economic Annals-XXI, vol. 3-4, no. 1, pp. 37-41.

Balakrishnan, R., Danninger, S., Elekdag, S., \& Tytell, I., (2011), The transmission of financial stress from advanced and emerging economies, Emerging Markets Finance and Trade, vol. 47, pp. 40-68.

Bank Negara Malaysia, (2009), Bank Negara Malaysia annual report 2009, Bank Negara Malaysia.

Brugemann, A., \& Linne, T., (2002), Are the central and Eastern European transition countries still vulnerable to a financial crisis? Results from the signals approach, Halle Institute for Economic Research, IWH Discussion Papers No. 157.

Cardarelli, R., Elekdag, S., \& Lall, S., (2011), Financial stress and economic contractions, Journal of Financial Stability, vol. 7, pp. 78-97. 
Cevik, E.I., Dibooglu, S., \& Kenc, T., (2013), Measuring financial stress in Turkey, Journal of Policy Modeling, vol. 35, pp. 370-383.

Chow, G., \& Lin, A., (1971), Best linear unbiased interpolation, distribution, and extrapolation of time series by related series, The Review of Economics and Statistics, vol. 53, pp. 372-375.

Christiano, L. J., \& Fitzgerald, T. J., (2003), The band pass filter, International Economic Review, vol. 44, no. 2, pp. 435-465.

Claessens, S., \& Kose, M. A., (2013), Financial crises: Explanations, types, and implications, International Monetary Fund, IMF Working Paper Series No. 28.

Drehmann, M., \& Juselius, M., (2014), Improving EWIs for banking crises - satisfying policy requirements, International Journal of Forecasting, vol. 30, no. 3, pp. 759-780.

Edison, H. J., (2003), Do indicators of financial crises work? An evaluation of an early warning system, International Journal of Finance and Economics, vol. 8, pp. 11-53.

Hakkio, S. C., \& Keeton, W. R., (2009), Financial stress: What is it, how can it be measured, and why does it matter? Federal Reserve Bank of Kansas City Economic Review, Second Quarter, pp. 5-50.

Illing, M., \& Liu, Y., (2006), Measuring financial stress in a developed country: An application to Canada, Journal of Financial Stability, vol. 2, pp. 243-265.

International Monetary Fund, (2017), 2017 Article IV consultation - press release, IMF Country Report No. 101, International Monetary Fund.

Jayaraman, T. K., Choong, C. K., \& Ng, C. F., (2017), Foreign direct investment and growth of India: Does financial sector development help in improving absorptive capacity?, International Journal of Business and Society, vol. 18, no. 1, pp. 171-188.

Kaminsky, G., \& Reinhart, C. M., (1996), The twin crises: The causes of banking and balance-of-payments problems, Board of Governors of the Federal Reserve System, International Finance Discussion Paper No. 544.

Kaminsky, G. L., \& Reinhart, C. M., (1999), The twin crises: the causes of banking and balance-of-payments problems, The American Economic Review, vol. 89, no. 3, pp. 473-500.

Megersa, K., \& Cassimon, D., (2015), Assessing indicators of currency crisis in Ethiopia: Signals approach, African Development Review, vol. 27, no. 3, pp. 315-330.

Nguyen, T., \& Duy, N. N., (2017), Developing an early warning system for financial crises in Vietnam, Asian Economic and Financial Review, vol. 7, no. 4, pp. 413-430.

Pesaran, M. H., \& Timmermann, A., (1992), A simple nonparametric test of predictive performance, Journal of Business and Economic Statistics, vol. 10, pp. 461-465.

Pesaran, M. H., \& Timmermann, A., (2009), Testing dependence among serially correlated multi-category variables, Journal of the American Statistical Association, vol. 485, pp. 325-337.

Puah, C. H., Kuek, T. H., \& Arip M. A., (2017), Assessing Thailand's financial vulnerability: An early warning approach, Business and Economic Horizons, vol. 13, no. 4, pp. 496505.

Puah, C. H., Kuek, T. H., Arip M. A., \& Wong, S. S. L., (2016), Forecasting property market dynamics: Insights from the property cycle indicator, Information, vol. 19, no. 6(B), pp. 2225-2232. 